\title{
Guidance for the use of bilateral internal thoracic arteries according to survival benefit across age groups
}

\author{
Umberto Benedetto, MD, PhD, Mohamed Amrani, MD, PhD, FETCS, FRCS, and \\ Shahzad G. Raja, MRCS, FRCS(C-Th), on behalf of the Harefield Cardiac Outcomes Research Group
}

\begin{abstract}
Objective: Increasing evidence from observational cohort studies supports a survival advantage from bilateral internal thoracic artery (BITA) relative to single internal thoracic artery (SITA) grafts in patients undergoing coronary artery bypass grafting. Whether the survival benefit from BITA is related to patient age and any potential age cutoff for the loss of survival benefit from BITA remain to be determined.
\end{abstract}

\begin{abstract}
Methods: Flexible parametric spline survival model was used to investigate the survival benefit from BITA across patient age groups. The study population consisted of 4190 patients undergoing coronary artery bypass grafting with SITA $(\mathrm{n}=3442 ; 81 \%)$ or BITA $(\mathrm{n}=748 ; 19 \%)$.

Results: A total of 376 deaths (BITA, $n=29$; SITA, $n=347$ ) were recorded after a mean follow-up of $4.9 \pm 3.2$ years (maximum, 12.2 years). Nonparametric survival probabilities at 1-, 5-, and 10-year follow-ups were $94.9 \% \pm 0.3 \%$ versus $98.0 \% \pm 0.5 \%, 90.7 \% \pm 0.5 \%$ versus $95.5 \% \pm 0.9 \%$, and $84.2 \% \pm 1.0 \%$ versus $93.7 \% \pm 1.4 \%$ in the SITA and BITA groups, respectively. Interaction between age and BITA (age*BITA) was found to affect survival significantly (coefficient, 0.056; SE, 0.02; $P=.015$ ). BITA was associated with reduced risk of mortality in patients aged 69 years and younger (fully adjusted hazard ratio, 0.49; 95\% confidence interval, 0.24-0.98; $P=.04$ ). On the other hand, for patients aged older than 69 years, BITA did not add any significant survival advantage (adjusted hazard ratio, $1.27 ; 95 \%$ confidence interval, $0.75-2.14$; $P=.37)$.
\end{abstract}

Conclusions: This study provides robust scientific evidence for the loss of survival benefit from BITA for patients older than 69 years. (J Thorac Cardiovasc Surg 2014;148:2706-11)

The use of single left internal thoracic artery (SITA) to the left anterior descending artery and saphenous vein grafts (SVGs) for non-left anterior descending artery targets is the standard approach in coronary artery bypass grafting $(\mathrm{CABG}){ }^{1}$ This conduit selection has been consistently shown to provide increased survival benefit and freedom from myocardial infarction, symptoms of ischemic heart disease, and reinterventions relative to CABG with SVGs only. ${ }^{1}$

Although increasing evidence from observational cohort studies supports a survival advantage from bilateral internal thoracic artery (BITA) relative to SITA, ${ }^{2}$ there still remains doubt as to whether BITA is the better choice for patients in the long term as the only randomized controlled trial to date evaluating long-term survival (the Arterial Revascularisation Trial) is still ongoing. ${ }^{3}$ Despite the increasing age of

From the Department of Cardiac Surgery, Harefield Hospital, London, United Kingdom.

Disclosures: Authors have nothing to disclose with regard to commercial support. Received for publication Jan 17, 2014; revisions received June 27, 2014; accepted for publication July 13, 2014; available ahead of print Sept 8, 2014.

Address for reprints: Umberto Benedetto, MD, PhD, Department of Cardiac Surgery, Harefield Hospital, London UB9 6JH, United Kingdom (E-mail: umberto. benedetto@hotmail.com).

$0022-5223 / \$ 36.00$

Copyright (c) 2014 by The American Association for Thoracic Surgery

http://dx.doi.org/10.1016/j.jtcvs.2014.07.088 patients undergoing CABG these days, BITA is preferentially used for younger patients only. This is because the common perception of a survival benefit is limited to subjects with long life expectancy. ${ }^{4}$ This aspect may partially account for the observed underuse of BITA grafts. ${ }^{5}$ Whether the survival benefit from BITA is related to the patient's age remains to be determined, however, as does any potential age cutoff for the loss of survival benefit from BITA. ${ }^{6-8}$ This information is expected to provide evidence for the decision-making process in selecting patients for BITA.

We aimed to investigate the potential benefit from BITA relative to the conventional strategy with SITA and SVGs in terms of long-term survival across patient age groups.

\section{MATERIALS AND METHODS Study Population}

The study was conducted in accordance with the principles of the Declaration of Helsinki. The local ethical committee approved the study, and the requirement for individual patient consent was waived. We retrospectively analyzed prospectively collected data from the institutional surgical database (PATS; Dendrite Clinical Systems, Ltd, Oxford, UK) from April 2001 to May 2013. The PATS database captures detailed information on a wide range of preoperative, intraoperative, and hospital postoperative variables (including complications and mortality) for all patients undergoing CABG in our institution. The data are collected and reported in accordance with the Society for Cardiothoracic Surgery in Great Britain \& Ireland database criteria. The database is maintained by 


\section{Abbreviations and Acronyms}

AIC = Akaike information criterion

BITA $=$ bilateral internal thoracic artery

$\mathrm{CABG}=$ coronary artery bypass grafting

$\mathrm{CI}=$ confidence interval

SITA $=$ single internal thoracic artery

SVG = saphenous vein graft

a team of full-time clinical information analysts, who are responsible for continuous prospective data collection as part of a continuous audit process. Data collection is validated regularly.

Cases included in the final analysis met the following criteria: (1) first-time isolated CABG; (2) multivessel disease (3) at least 2 grafts received; (4) surgical strategies included single left internal thoracic artery to the left anterior descending artery and additional SVG (SITA group) or BITA with or without additional SVG (BITA group). Conduit selection was based on the surgeon's preference. Patients receiving the radial artery or the right gastroepiploic artery were not included in this analysis.

\section{Pretreatment Variables and Study End Point}

The effect of BITA was adjusted for the following 19 pretreatment variables: age, female sex, previous New York Heart Association functional class III or IV, previous myocardial infarction, previous percutaneous coronary intervention, diabetes mellitus, current smoking, chronic obstructive pulmonary disease, cerebrovascular accident, peripheral vascular disease, history of atrial fibrillation, left main disease, number of vessels diseased, left ventricular ejection fraction less than $50 \%$, serum creatinine level greater than $200 \mathrm{mmol} / \mathrm{L}$, body mass index, urgent or emergency indication, surgery performed by resident, and the use of cardiopulmonary bypass.

The primary end point was all-cause mortality. All-cause mortality is the most robust and unbiased index, because no adjudication is required, thus avoiding inaccurate or biased documentation and clinical assessments. ${ }^{9}$ Information about death from any cause is regularly obtained from the General Register Office approximately 1 week after the event. The General Register Office is the section of Her Majesty's Passport Office responsible for recording deaths in the United Kingdom, or outside the United Kingdom if the death involves a UK citizen.

\section{Statistical Analysis}

For baseline characteristics, variables are summarized as means for continuous variables and proportions for categoric variables.

Multiple imputation with a bootstrapping-based expectationmaximization algorithm was used to address missing data. The fraction of missing ranged from $0 \%$ (age) to $0.8 \%$ (body mass index). Patterns of missingness in the data were 45 , and rows after listwise deletion were 3695. The imputation model showed normal expectation-maximization convergence. The Amelia R statistical software ${ }^{10}$ package was used for this analysis.

To account for multiphase hazard function, BITA effect on survival was assessed with flexible parametric modelling of time-to-event data testing the following models: Weibull, log-logistic and the spline model of Royston and Parmar. ${ }^{11}$ The flexsurv R package (Jackson C. 2014 Jan 20. flexsurv: Flexible parametric survival models; http://CRAN.R-project. org/package $=$ flexsurv) was used. The fitted model was selected according to the Akaike information criterion (AIC), ${ }^{12}$ and the agreement between fitted parametric model and nonparametric survival estimates was visually checked. Check for age linearity was assessed with the likelihood ratio test including age as a linear term or spline fit (quadratic). To investigate the potential interaction effect between a patient's age and BITA grafting on survival advantage, a second-order interaction between the treatment indicator (BITA) and patient's age was forced into the final survival model. To identify the potential age cutoff for the loss of survival benefit from BITA grafting, the adjusted hazard ratio for BITA relative to SITA, with its $95 \%$ confidence interval $(\mathrm{CI})$, was calculated across patient age and plotted with the cubic spline method.

The $\mathrm{R}$ software package ( $\mathrm{R}$ Core Team. 2012. R: A language and environment for statistical computing. version 2.15.2; http://www. $\mathrm{R}$-project.org) was used for the various statistical analyses.

\section{RESULTS}

The study population consisted of 4190 patients undergoing CABG with SITA $(\mathrm{n}=3442 ; 81 \%)$ or BITA $(\mathrm{n}=748 ; 19 \%)$. Table 1 shows the pretreatment covariate distribution between the 2 groups. The 2 groups differed significantly in 14 of 19 pretreatment variables. Overall, patients undergoing SITA presented a higher risk profile, including the proportion of patients older than 70 years.

\section{Thirty-Day Mortality}

A total of 90 of the 4190 patients $(2.1 \%)$ died within 30 days, with 5 of $748(0.6 \%)$ and 85 of $3442(2.4 \%)$ deaths recorded in the BITA and SITA groups, respectively (unadjusted $P=.004$ ). Crude mortalities in age groups for BITA and SITA, respectively, were 2 of $360(0.5 \%)$ versus 4 of $680(0.5 \%)$ among patients younger than 60 years, 3 of $267(1.1 \%)$ versus 22 of $1098(2.0 \%)$ among patients aged between 60 and 69 years, 0 of $108(0 \%)$ versus 42 of $1378(3.0 \%)$ among patients aged between 70 and 79 years, and 0 of $13(0 \%)$ versus 17 of 286 $(5.9 \%)$ among patients aged 80 years or older.

\section{Survival Analysis}

A total of 376 deaths (BITA, $n=29 ;$ SITA, $n=347$ ) were recorded after a mean follow-up of $4.9 \pm 3.2$ years (maximum of 12.2 years). Nonparametric overall survival probabilities at 1-, 5- and 10-year follow-up were $95.5 \% \pm 0.3 \%, 91.5 \% \pm 0.4 \%$, and $85.8 \% \pm 0.8 \%$. Nonparametric survival probabilities at 1-, 5-, and 10-year follow-up were $94.9 \% \pm 0.3 \%$ versus $98.0 \% \pm 0.5 \%$, $90.7 \% \pm 0.5 \%$ versus $95.5 \% \pm 0.9 \%$ and $84.2 \% \pm$ $1.0 \%$ versus $93.7 \% \pm 1.4 \%$ in the SITA and BITA groups, respectively. The flexible spline model showed the best fit (AIC of 3320) when compared with the Weibull model (AIC of 3362) and the log logistic model (AIC of 3365). Excellent agreement was seen between nonparametric and flexible parametric spline survival curves (Figure 1). The likelihood ratio test suggested that a linear term for age was adequate, and the quadratic term did not yield a better fit (linear $\chi^{2}=131$; quadratic $\chi^{2}=133$; analysis of variance $P=.63$ ). Table 2 shows association between covariates and survival with univariate and multivariate flexible spline models. Interaction between age and BITA (age*BITA) was found to significantly affect survival (coefficient, 0.056 ; SE, .02; $P=.015$ ). The survival benefit from 
TABLE 1. Pretreatment variables in patients receiving bilateral internal thoracic arteries or single internal thoracic artery

\begin{tabular}{|c|c|c|c|}
\hline & $\begin{array}{c}\text { BITA } \\
(\mathbf{N}=\mathbf{7 4 8})\end{array}$ & $\begin{array}{c}\text { SITA } \\
(\mathrm{N}=\mathbf{3 4 4 2})\end{array}$ & $\begin{array}{c}P \\
\text { value }\end{array}$ \\
\hline Age $(y$, mean \pm SD $)$ & $60 \pm 10$ & $68 \pm 9$ & $<.001$ \\
\hline \multicolumn{4}{|l|}{ Age group } \\
\hline$<60 \mathrm{y}$ & $360(48 \%)$ & $680(20 \%)$ & \\
\hline $60-70 \mathrm{y}$ & $267(36 \%)$ & $1098(32 \%)$ & \\
\hline $70-75$ y & $64(9 \%)$ & $786(23 \%)$ & \\
\hline $5-80$ y & $44(5 \%)$ & $592(17 \%)$ & \\
\hline$>80 \mathrm{y}$ & $13(2 \%)$ & $286(8 \%)$ & \\
\hline Female (no.) & $82(11 \%)$ & $726(21 \%)$ & $<.001$ \\
\hline NYHA III/IV (no.) & $149(20 \%)$ & $1067(31 \%)$ & $<.001$ \\
\hline MI (no.) & $299(40 \%)$ & $1445(42 \%)$ & .45 \\
\hline PCI (no.) & $134(18 \%)$ & $481(14 \%)$ & .004 \\
\hline DM (no.) & $119(16 \%)$ & $1101(32 \%)$ & $<.001$ \\
\hline Active smoking (no.) & $89(12 \%)$ & $344(10 \%)$ & .09 \\
\hline COPD (no.) & $59(8 \%)$ & $378(11 \%)$ & .02 \\
\hline CVA (no.) & $22(3 \%)$ & $240(7 \%)$ & $<.001$ \\
\hline PVD (no.) & $44(6 \%)$ & $309(9 \%)$ & .008 \\
\hline AF (no.) & $14(2 \%)$ & $103(3 \%)$ & .085 \\
\hline NVD $($ mean \pm SD) & $2.69 \pm 0.5$ & $2.73 \pm 0.4$ & .04 \\
\hline LAD + diagonal (no.) & $15(2 \%)$ & $76(2 \%)$ & \\
\hline $\mathrm{LAD}+\mathrm{Cx}$ or RCA (no.) & $203(27 \%)$ & $770(22 \%)$ & \\
\hline $\mathrm{LAD}+\mathrm{Cx}+\mathrm{RCA}($ no.) & $530(71 \%)$ & $2596(76 \%)$ & \\
\hline LMD (no.) & $246(33 \%)$ & $998(29 \%)$ & .08 \\
\hline LVEF $<50 \%$ (no.) & $97(13 \%)$ & $757(22 \%)$ & $<.001$ \\
\hline Urgent or emergency indication (no.) & $216(29 \%)$ & $1135(33 \%)$ & .01 \\
\hline Performed by resident (no.) & $216(29 \%)$ & $1307(38 \%)$ & $<.001$ \\
\hline CPB (no.) & $216(29 \%)$ & $1204(35 \%)$ & $<.001$ \\
\hline BMI $\left(\mathrm{kg} / \mathrm{m}^{2}\right)$ & 27.51 & 28.01 & .005 \\
\hline Creatinine $\geq 200 \mu \mathrm{mol} / \mathrm{L}$ (no.) & $14(2 \%)$ & $103(3 \%)$ & .051 \\
\hline IABP (no.) & $14(2 \%)$ & $137(4 \%)$ & .04 \\
\hline
\end{tabular}

BITA, Bilateral internal thoracic arteries; SITA, single internal thoracic artery; NYHA, New York Heart Association functional class; $M I$, myocardial infarction; $P C I$, percutaneous coronary intervention; $D M$, diabetes mellitus; $C O P D$, chronic obstructive pulmonary disease; $C V A$, cerebrovascular accident; $P V D$, peripheral vascular disease; $A F$, atrial fibrillation; $N V D$, number of vessels diseased; $L A D$, left anterior descending coronary artery; $C x$, circumflex coronary artery; $R C A$, right coronary artery; $L M D$, left main disease; $L V E F$, left ventricular ejection fraction; $C P B$, cardiopulmonary bypass; $B M I$, body mass index; $I A B P$, intra-aortic balloon pump; $S D$, standard deviation.

BITA grafting was not equally present across all age groups, as shown by spline analysis (Figure 2); in fact, it was maximal for patients aged 61 years or younger (upper limit of $95 \% \mathrm{CI}<1$ ). The survival advantage conferred by BITA use gradually declined with increasing patient age, and it was no longer present beyond 69 years of age.

An age of 69 years was then considered as the cutoff point, and it provided good discrimination for the age-related loss of survival benefit from the BITA. BITA was associated with reduced risk of mortality for patients aged 69 years and younger, with 15 deaths among 627 subjects receiving BITA versus 118 deaths among 1778 subjects receiving SITA (fully adjusted hazard ratio, 0.49; 95\% CI, 0.24-0.98; $P=.04)$. The instantaneous risk of death was lower in the BITA group during both early and late phases (Figure 3). On the other hand, for patients older than 69 years, BITA did not add any significant survival advantage, with $14(13.6 \%)$ deaths among 121 subjects receiving BITA $(3.16 \%$ per year) versus 102 deaths $(14.5 \%)$ among 1652 subjects receiving SITA $(3.02 \%$ per year; adjusted hazard ratio, 1.27 ; $95 \%$ CI, $0.75-2.14$; $P=.37)$.

\section{DISCUSSION}

This study shows that BITA provided a survival benefit related to patient age at the time of CABG. This benefit progressively declined with age, although it remained clinically significant until the age of 69 years.

Improvement of survival is largely considered the most important scope of coronary revascularization. ${ }^{1}$ Additional arterial grafts, ${ }^{13}$ including BITA, ${ }^{2}$ have been proposed to improve late survival after $\mathrm{CABG}$, but definitive conclusions are still lacking.

Whether BITA is the better choice for patients in the long term is still debated. ${ }^{3,5,7}$ Despite the improved long-term outcome, the application of this technique in the elderly population remains controversial because of their shorter life expectancy and the excellent survival benefit obtained with SITA. Whether the survival benefit from BITA is age dependent and the potential age cutoff for the loss of survival benefit remain to be determined.

To date, sporadic reports have previously addressed this issue and reached conflicting conclusions. Mohammadi and colleagues ${ }^{4}$ conducted a retrospective analysis on 1388 patients receiving BITA, and they concluded that BITA provided survival advantage only for patients younger than 60 years. In contrast, Kurlansky and coworkers ${ }^{6}$ found that BITA improved survival across all patient age classes, thus failing to show age as an effect modifier on survival benefit from BITA. Kieser and associates ${ }^{7}$ investigated the impact of BITA on late survival in a population of 1038 patients. They suggested age as an effect modifier on survival benefit from BITA, but their analysis failed to show a significant impact of BITA across all age classes after adjustment for clinical variables. Toumpoulis and colleagues $^{8}$ analyzed the impact of BITA on survival in patients with diabetes. They found no difference in 5-year survival for patients younger than 60 or for those from 70 to 79 years old, but BITA did improve survival in patients aged 60 to 69 years. It should be underlined that the age cutoff in the previously mentioned studies was not derived from the analysis of the effect of BITA across all patient ages but was chosen arbitrarily, and this aspect makes the study conclusions questionable.

This study investigated the effect of age on survival benefit from BITA relative to SITA with a parametric survival model adjusted for 19 pretreatment variables. The interaction of age and BITA showed the age of 69 years as a cutoff for the loss of survival benefit from BITA. 

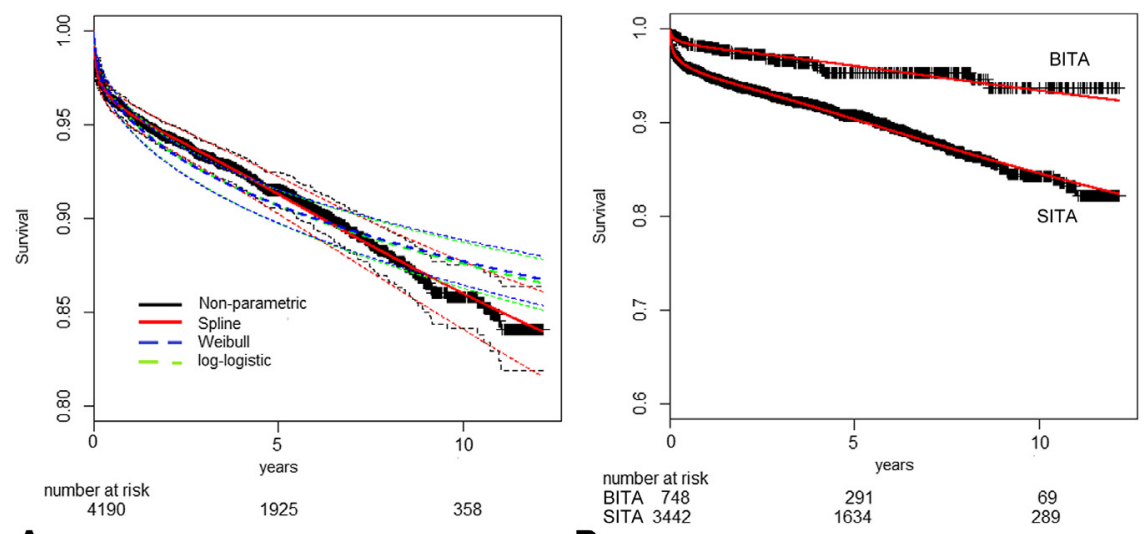

A

B

FIGURE 1. A, Agreement between nonparametric (black) and flexible parametric (spline, red; Weibull, dashed blue; log logistic, dashed green) survival curves in the overall study population. B, Agreement between nonparametric (black) and flexible spline parametric (red) survival curves in the bilateral internal thoracic artery (BITA) and single internal thoracic artery (SITA) groups.

It can be speculated that the risk of death from noncardiac causes increases with increasing age, thus neutralizing the effect of BITA grafting on cardiac-related death. Moreover, the loss of significant survival benefit from BITA grafting in older patients might be related to their shorter life expectancy, with patient age per se overshadowing the potential advantage gained with BITA. On the other hand, in younger patients ( $\leq 69$ years), the beneficial effect of
BITA grafting on cardiac-related death might account for the observed improved overall survival. The survival benefit from BITA was found to be present in both early and late phases of the hazard function. It has been recognized that the observed saphenous vein failure occurs in as many as $25 \%$ of cases $^{14}$ within 1 year after CABG. Early vulnerability of SVG might explain the early survival benefit observed among patients receiving BITA. $^{15}$

TABLE 2. Univariate and multivariate parametric survival models

\begin{tabular}{|c|c|c|c|c|c|c|}
\hline & \multicolumn{3}{|c|}{ Univariate analysis } & \multicolumn{3}{|c|}{ Multivariate analysis } \\
\hline & HR & $95 \%$ CI & $P$ value & HR & $95 \% \mathrm{CI}$ & $P$ value \\
\hline Age & 1.08 & $1.06-1.09$ & $<.0001$ & 1.06 & $1.05-1.08$ & $<.0001$ \\
\hline Female & 1.35 & $1.05-1.73$ & .0183 & 1.14 & $0.87-1.49$ & .3452 \\
\hline NYHA III/IV & 2.12 & $1.71-2.63$ & $<.0001$ & 1.52 & $1.21-1.93$ & .0005 \\
\hline MI & 1.58 & $1.27-1.95$ & $<.0001$ & 1.2 & $0.95-1.51$ & .1230 \\
\hline PCI & 0.82 & $0.59-1.14$ & .2400 & - & - & - \\
\hline DM & 1.66 & $1.33-2.07$ & $<.0001$ & 1.45 & $1.14-1.84$ & .0024 \\
\hline Active smoking & 0.84 & $0.58-1.22$ & .3640 & - & - & - \\
\hline COPD & 1.55 & $1.12-2.13$ & .0075 & 1.3 & $0.92-1.82$ & .1318 \\
\hline CVA & 2.16 & $1.52-3.07$ & $<.0001$ & 1.45 & $1-2.11$ & .0507 \\
\hline PVD & 1.76 & $1.27-2.45$ & .0008 & 1.23 & $0.86-1.74$ & .2523 \\
\hline $\mathrm{AF}$ & 3.33 & $2.16-5.12$ & $<.0001$ & 2.05 & $1.3-3.23$ & .0020 \\
\hline NVD & 1.12 & $0.89-1.41$ & .3396 & - & - & - \\
\hline LMD & 1.29 & $1.03-1.62$ & .0273 & 1.06 & $0.83-1.35$ & .6515 \\
\hline LVEF $<50 \%$ & 2.44 & $1.94-3.06$ & $<.0001$ & 1.64 & $1.27-2.11$ & .0001 \\
\hline Urgent or emergency & 1.89 & $1.52-2.36$ & $<.0001$ & 1.33 & $1.03-1.7$ & .0255 \\
\hline Performed by resident & 0.72 & $0.58-0.91$ & .0043 & 0.9 & $0.71-1.15$ & .3988 \\
\hline $\mathrm{CPB}$ & 1.33 & $1.07-1.66$ & .0109 & 1.31 & $1.04-1.65$ & .0217 \\
\hline BMI & 0.03 & $0.002-0.44$ & .0108 & 0.04 & $0.002-0.71$ & .0314 \\
\hline Creatinine $\geq 200 \mathrm{mmol} / \mathrm{L}$ & 3.06 & $1.94-4.84$ & $<.0001$ & 1.8 & $1.11-2.93$ & .0175 \\
\hline IABP & 3.06 & $2-4.69$ & $<.0001$ & 2.13 & $1.33-3.41$ & .0017 \\
\hline BITA & 0.388 & $0.263-0.573$ & $<.0001$ & 0.02 & $0.0007-0.49$ & .0191 \\
\hline Age*BITA* & - & - & - & 1.06 & 1.01-1.11 & .0155 \\
\hline
\end{tabular}




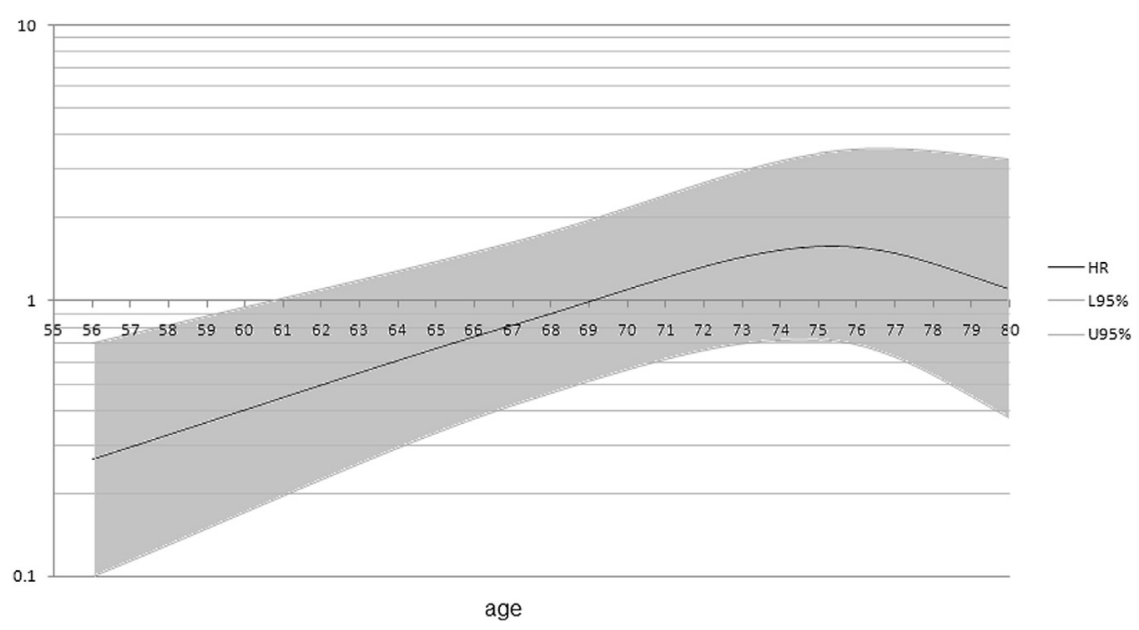

FIGURE 2. Hazard ratios $(H R)$ and $95 \%$ confidence interval lower $(L 95 \%)$ and upper (U95\%) bounds for bilateral internal thoracic artery grafting versus single internal thoracic artery grafting according to patients age at surgery.

Moreover, the superior patency rate of BITA relative to $\mathrm{SVG}$ is further enhanced with longer follow-up. ${ }^{16}$ The significant risk reduction for mortality among patients aged 69 years or younger thus may result from the combined early- and late phase benefits of using BITA grafting.
There are limitations to this study. It is observational, and we acknowledge that the revascularization strategies occurred in a nonrandom fashion. We used a data set rich in clinical detail, and although we had the ability to control for important potential confounding variables, it is possible
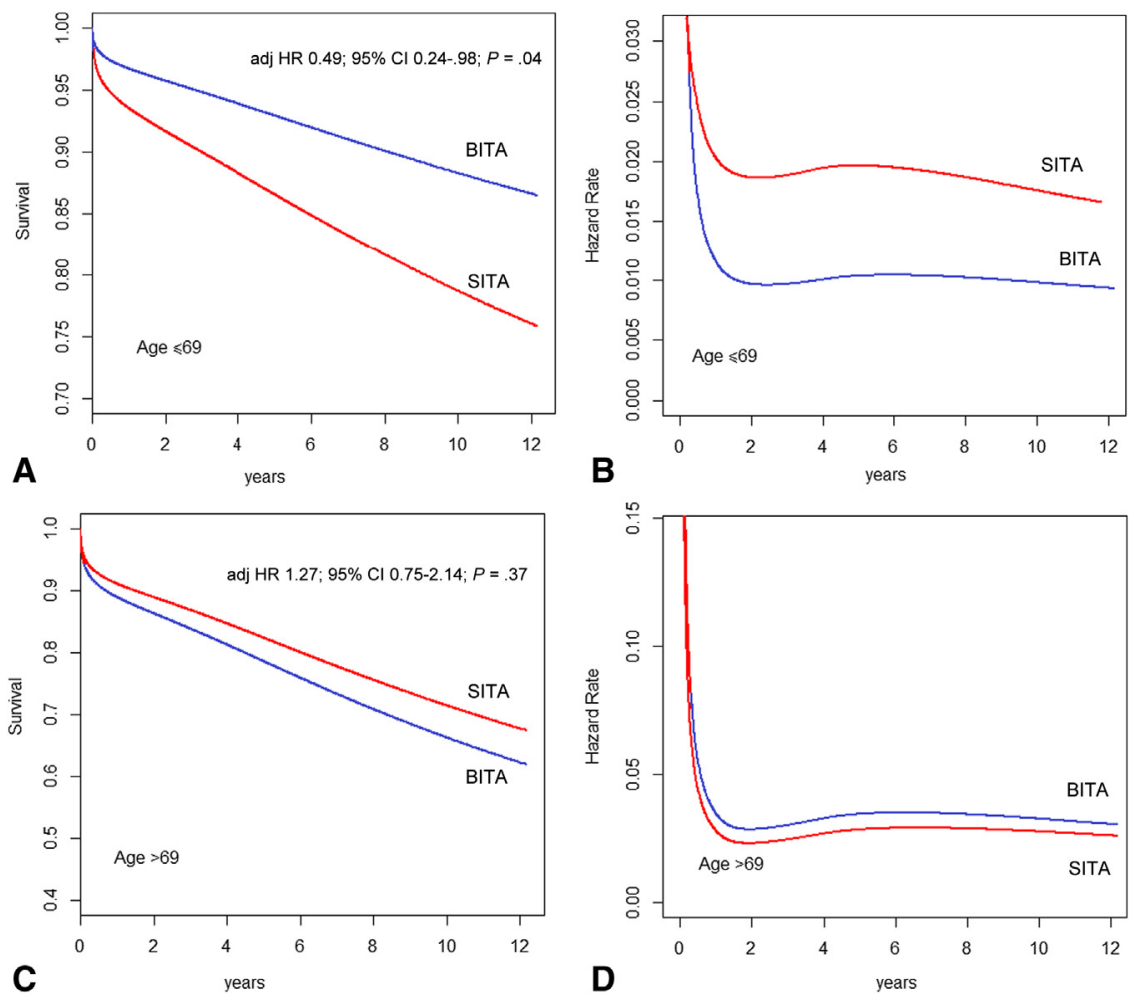

FIGURE 3. Estimated survival ( $A$ and C) and hazard (B and D) functions for patients aged 69 years or younger (A and B) and patients older than 69 years (C and D) receiving bilateral internal thoracic artery grafts (BITA, blue) or single internal thoracic artery grafts (SITA, red). Estimates at means of the following covariates: New York Heart Association functional class, myocardial infarction, diabetes mellitus, chronic obstructive pulmonary disease, cerebrovascular accident, peripheral vascular disease, atrial fibrillation, left ventricular ejection fraction, cardiopulmonary bypass, body mass index, and intra-aortic balloon pump. adj, Adjusted; $H R$, hazard ratio; $C I$, confidence interval. 
that other factors not accounted for in our analysis (eg, patient fitness) are associated with both selection of BITA grafting and outcome. In addition, BITA grafting was performed by the surgeons most comfortable with the procedure and not uniformly performed by all. We are unable to attribute the improved survival unambiguously to the effects of BITA use, specifically the presumed enhanced patency rates, because neither the cause of death nor graft patency data were available. All-cause death is recommended to be considered in studies investigating results of coronary intervention as a more reliable end point than cause-specific mortality ${ }^{9}$; however, this is only one of the outcomes relevant to the elderly population, and our study has not analyzed other important effects, such as improvement in quality of life, recurrent ischemia or angina, or need for repeated revascularization. Finally, in this analysis the number of subjects receiving BITA and the number of deaths in the BITA group were relatively small, and this in particular might have caused loss of accuracy in the analysis.

In conclusion, our results provide scientific evidence for an age cutoff for the loss of benefit from BITA. This robust evidence supports the use of BITA in patients aged 69 years and younger. Although a benefit extending into older age cannot be formally excluded, ${ }^{17}$ the lack of evidence for further survival benefit from BITA in older patients and the potential risk for sternal wound infection related to BITA use $^{18}$ suggest the need to use clinical judgment in the selection of grafts for the older segment of the surgical population.

We thank all consultant cardiac surgeons who have operated at Harefield Hospital during the study period for their contribution: M. Amrani, T. Bahrami, F. de Robertis, G. Dreyfus, J. Gaer, A. Khaghani, A. Moza, S. G. Raja, A. Simon, and S. Tadjkarimi.

\section{References}

1. Loop FD, Lytle BW, Cosgrove DM, Stewart RW, Goormastic M, Williams GW, et al. Influence of the internal-mammary-artery graft on 10-year survival and other cardiac events. $N$ Engl J Med. 1986;314:1-6.

2. Lytle BW, Blackstone EH, Loop FD, Houghtaling PL, Arnold JH, Akhrass R, et al. Two internal thoracic artery grafts are better than one. J Thorac Cardiovasc Surg. 1999;117:855-72.
3. Taggart DP, Altman DG, Gray AM, Lees B, Nugara F, Yu LM, et al; ART Investigators. Randomized trial to compare bilateral vs. single internal mammary coronary artery bypass grafting: 1-year results of the Arterial Revascularisation Trial (ART). Eur Heart J. 2010;31:2470-81.

4. Mohammadi S, Dagenais F, Doyle D, Mathieu P, Baillot R, Charbonneau E, et al. Age cut-off for the loss of benefit from bilateral internal thoracic artery grafting. Eur J Cardiothorac Surg. 2008;33:977-82.

5. Tatoulis J, Buxton BF, Fuller JA. The right internal thoracic artery: is it underutilized? Curr Opin Cardiol. 2011;26:528-35.

6. Kurlansky PA, Traad EA, Dorman MJ, Galbut DL, Zucker M, Ebra G. Thirty-year follow-up defines survival benefit for second internal mammary artery in propensity-matched groups. Ann Thorac Surg. 2010;90:101-8.

7. Kieser TM, Lewin AM, Graham MM, Martin BJ, Galbraith PD, Rabi DM, et al; APPROACH Investigators. Outcomes associated with bilateral internal thoracic artery grafting: the importance of age. Ann Thorac Surg. 2011;92:1269-75; discussion 1275-6.

8. Toumpoulis IK, Anagnostopoulos CE, Balaram S, Swistel DG, Ashton RC Jr, DeRose JJ Jr. Does bilateral internal thoracic artery grafting increase long-term survival of diabetic patients? Ann Thorac Surg. 2006;81:599-606; discussion 606-7.

9. Holmes DR Jr, Kip KE, Kelsey SF, Detre KM, Rosen AD. Cause of death analysis in the NHLBI PTCA Registry: results and considerations for evaluating long-term survival after coronary interventions. J Am Coll Cardiol. 1997;30: $881-7$.

10. Honaker J, King G, Blackwell M. Amelia II: a program for missing data. J Stat Software. 2011;45:1-47.

11. Royston P, Parmar M. Flexible parametric proportional-hazards and proportional-odds models for censored survival data, with application to prognostic modelling and estimation of treatment effects. Stat Med. 2002;21: 2175-97.

12. Zucchini W. An Introduction to model selection. J Math Psychol. 2000;44 41-61.

13. Benedetto U, Codispoti M. Age cutoff for the loss of survival benefit from use of radial artery in coronary artery bypass grafting. J Thorac Cardiovasc Surg. 2013; 146:1078-84; discussion 1084-5.

14. Magee MJ, Alexander JH, Hafley G, Ferguson TB Jr, Gibson CM Harrington RA, et al; PREVENT IV Investigators. Coronary artery bypass graft failure after on-pump and off-pump coronary artery bypass: findings from PREVENT IV. Ann Thorac Surg. 2008;85:494-9; discussion 499500 .

15. Halabi AR, Alexander JH, Shaw LK, Lorenz TJ, Liao L, Kong DF, et al. Relation of early saphenous vein graft failure to outcomes following coronary artery bypass surgery. Am J Cardiol. 2005;96:1254-9.

16. Cao C, Ang SC, Wolak K, Peeceeyen S, Bannon P, Yan TD. A meta-analysis of randomized controlled trials on mid-term angiographic outcomes for radial artery versus saphenous vein in coronary artery bypass graft surgery. Ann Cardiothorac Surg. 2013;2:401-7.

17. Raja SG. Myocardial revascularization for the elderly: current options, role of off-pump coronary artery bypass grafting and outcomes. Curr Cardiol Rev. 2012;8:26-36

18. Nakano J, Okabayashi H, Hanyu M, Soga Y, Nomoto T, Arai Y, et al. Risk factors for wound infection after off-pump coronary artery bypass grafting should bilateral internal thoracic arteries be harvested in patients with diabetes? J Thorac Cardiovasc Surg. 2008;135:540-5. 